\title{
Ballistic performance of nanocrystalline and nanotwinned ultrafine crystal steel
}

\author{
Jaime Frontán ${ }^{\mathrm{a}}$, Yuming Zhang ${ }^{\mathrm{b}, \mathrm{c}}$, Ming Dao ${ }^{\mathrm{c}}$, Jian $\mathrm{Lu}^{\mathrm{d}}$, \\ Francisco Gálvez ${ }^{\text {, }}$ Antoine Jérusalem ${ }^{\mathrm{e}, *}$
}

\begin{abstract}
Because of their remarkable mechanical properties, nanocrystalline metals have been the focus of much research in recent years. Refining their grain size to the nanometer range $(<100 \mathrm{~nm}$ ) effectively reduces their dislocation mobility, thus achieving very high yield strength and surface hardness - as predicted by the Hall-Petch relation - as well as higher strain-rate sensitivity. Recent works have additionally suggested that nanocrystalline metals exhibit an even higher compressive strength under shock loading. However, the increase in strength of these materials is generally accompanied by an important reduction in ductility. As an alternative, efforts have been focused on ultrafine crystals, i.e. polycrystals with a grain size in the range of $500 \mathrm{~nm}$ to $1 \mu \mathrm{m}$, in which "growth twins" (twins introduced inside the grain before deformation) act as barriers against dislocation movement, thus increasing the strength in a similar way as nanocrystals but without significant loss of ductility. Due to their outstanding mechanical properties, both nanocrystalline and nanotwinned ultrafine crystalline steels appear to be relevant candidates for ballistic protection. The aim of the present work is to compare their ballistic performance against coarse-grained steel, as well as to identify the effect of the hybridization with a carbon fiber-epoxy composite layer. Hybridization is proposed as a way to improve the nanocrystalline brittle properties in a similar way as is done with ceramics in other protection systems. The experimental campaign is finally complemented by numerical simulations to help identify some of the intrinsic deformation mechanisms not observable experimentally. As a conclusion, nanocrystalline and nanotwinned ultrafine crystals show a lower energy absorption than coarse-grained steel under ballistic loading, but under equal impact conditions with no penetration, deformation in the impact direction is smaller by nearly $40 \%$. This a priori surprising difference in the energy absorption is rationalized by the more important local contribution of the deviatoric stress vs. volumetric stress under impact than under uniaxial deformation. Ultimately, the deformation advantage could be exploited in the future for personal protection systems where a small deformation under impact is of key importance.
\end{abstract}

\section{Introduction}

Grain size refinement in metals, as achieved via cold working for some alloys [1], is widely accepted as a way to improve many of their mechanical properties [2,3]. More specifically, the material's strength is known to increase linearly with the inverse square root of the grain size below a given grain size- the direct Hall-Petch effect $[4,5]$ :

$\sigma_{y}=\sigma_{0}+k d^{-\frac{1}{2}}$

where $k$ is a positive multiplicative constant and $\sigma_{0}$ is the lattice friction stress. 
The pioneering work of Gleiter [6] showed that further grain size reduction down to the nanometer range $(<100 \mathrm{~nm})$ may lead to exceptional properties (e.g. ultrahigh strength) achievable by a wide range of materials with nanocrystalline structures such as metals and ceramics. Such improvement is related to the decreased mobility of dislocations in smaller grains, mainly due to dislocation pile-ups at grain boundaries acting as barriers, thus resulting in an increased yield stress. The decrease in grain sizes incidentally raises the volume fraction of grain boundaries, which are overwhelmingly high angle, high energy with low coherence, and drastically decreases the overall material ductility [7].

Very high strength has been reported in nanocrystalline metals such as copper [8,9] or steel [10-12]. However, these works all reveal a limit in the strength generally reached at a grain size of a few tenths of nanometers [13,2]. At these grain sizes, a shift in the main deformation mechanism takes place [8]. The dislocation pile-up model is no longer adequate at this scale [13], and a transition from intragranular to grain boundary mediated deformation takes place [14-18]. This, in turn, leads to a reduction in the strength, apparently also following Eq. (1) but with a negative $k$; the reverse Hall-Petch effect.

The glass-like amorphous state of nanocrystalline highangle grain boundaries has been observed to generate friction during grain boundary sliding $[19,20]$. Recent works have confirmed that this behavior is of prime relevance under compressive shock-loading conditions [21]. Under such conditions, the high compressive state coupled to the associated frictional behavior inhibits grain boundary sliding, forcefully reactivating intragranular plasticity as the only way to accommodate further deformation, and ultimately raising the material strength to even higher levels $[21,7]$.

As stated earlier, one main disadvantage of nanocrystalline materials is their low ductility. One proposed approach to bypass this restriction is to engineer coherent boundaries inside the grains acting as barriers against dislocations but without decreasing the ductility by conserving a relatively high coherence [22]. Nanoscale growth twins embedded in ultrafine crystals $(500 \mathrm{~nm}<d<1 \mu \mathrm{m}$ ) have be shown to fulfill this description by increasing the material strength with a decrease of twin spacing equivalent to the one observed with grain size in nanocrystals [23-28].

If the high strength of nanocrystalline (nc) and nanotwinned ultrafine crystals (nt-ufc) have been confirmed in several experiments, the ballistic impact behavior of such materials is still unknown. Study of this behavior appears as a logical step given the high strength, rate-dependency and ductility (for nt-ufc) of these materials.

Nowadays, most impact personal protection systems are based on synthetic fibers and composites $[29,30]$, and rely on hybrid configurations to improve their properties. In these hybrid configurations, the different properties of both (or more) materials are combined to create a series of differentiated deformation and/or fracture mechanisms able to defeat the projectile advance. The common approach is to place a hard strike face made of a hard metal [31] or ceramic [32], able to withstand the high compressive forces generated during the initial contact, and erode the softer projectile. An elastic, high-strength backing material absorbs the high tensile stress/deformation generated from the bending and/or pushing of the back of the plate [33]. $\mathrm{Nc}$ and nt-ufc steels a priori have the desired properties for a good performance both as strike face (high hardness) or as backing material (ultra-high tensile strength). The use of metals as the strike face, backed by fibers or composites [31], or as backing material for ceramic tiles [34] has already been proposed. The chosen material for hybridization in this study is an epoxy-matrix carbon fiber composite, Hexcel 8552. This is a relatively inexpensive material, widely used in aerospace industry, and presents a combination of good stiffness and high compressive strength and surface hardness.

The experimental campaign of this work is complemented by numerical continuum simulations. Analytical models have already been developed for both metals [3540] and composites [41-46]. The associated constitutive and failure mechanics models often make use of the Johnson-Cook plasticity model for metals [47] and complex fracture evolution models for composites [48-50]. We propose here to use a finite-element model with a JohnsonCook-type constitutive model for the metal. The model is then used to study the evolution of von Mises stress and pressure within the plate.

The work proposed here builds up on the preliminary results of Frontán et al. [51]. The overall aim is to determine the ballistic performance of nc and nt-ufc steel plates, and the optimal configuration for composite-steel hybrid plates. The selected materials, their processing techniques and a series of uniaxial tests at different strain rates are first presented in Section 2. The experimental set-up for the ballistic tests and their results are described in detail in Section 3. In Section 4, the numerical model is presented and the von Mises stress/pressure evolutions under impact loading are studied. The analysis of both experimental and numerical campaigns are then gathered in Section 5. The final conclusion as well as some practical applications of the results are ultimately presented in Section 6 .

\section{Test samples}

\subsection{Steel}

Nt-ufc and nc test samples were processed from $1 \mathrm{~mm}$ plates of coarse-grained AISI 304 stainless steel. A surface mechanical attrition treatment (SMAT) $[3,10,12,52-56]$ generated a gradient of ultrafine crystal grain sizes. This technique employs ultrasonic shot peening inside a closed chamber, filled with stainless steel balls $(1-10 \mathrm{~mm}$ diameter). Here, the treated plate forms one of the chamber's walls, and is impacted multiple times in a very short period when subjected to high-frequency vibrations $(20 \mathrm{kHz})$ for 


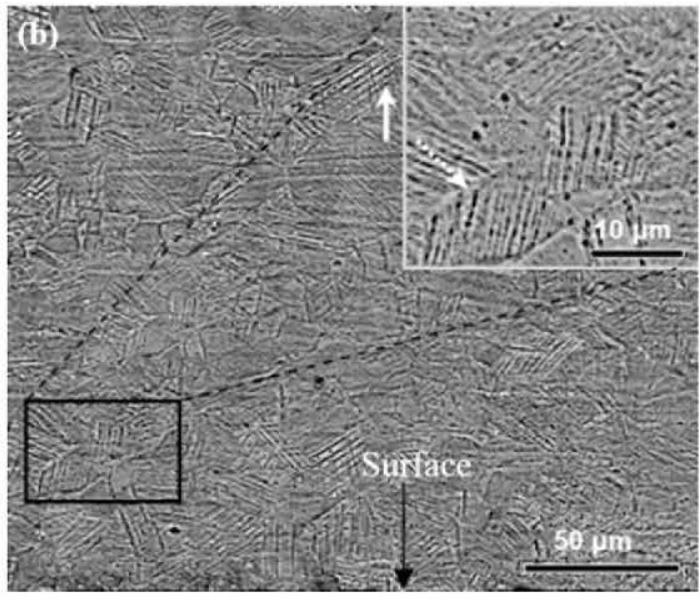

Fig. 1. Cross-sectional scanning electron microscopy observation of the SMAT sample [56].

$15 \mathrm{~min}$. This method is simple, relatively cheap and very flexible, as the frequency and ball size can be easily adjusted. It has been successfully employed with titanium [55], cobalt [57], copper [54] and several steels [11,10,56]. The SMAT method removes surface defects, producing samples with a high-quality surface.

The high-frequency SMAT used here leads to the formation of austenite nanotwinned ultrafine crystals on the top layers [56], see Fig. 1 (note that transmission electron microscopy images of the twins are also available in Figs. 6-8 of this same reference). For the sake of simplicity, the SMAT steel is referred to in the following as "nt-ufc steel", instead of "nanotwin enriched ultrafine crystalline steel".

The "nc steel" samples were obtained by subsequently coating the nt-ufc steel samples with a nitriding layer [12], further refining the grains to the nanoscale [58]. The plasma nitriding was accomplished at $450{ }^{\circ} \mathrm{C}$ for $1.5 \mathrm{~h}$ on both sides - see, for example, the evolution of the nanocrystallization for different SMAT durations coupled to plasma nitriding in Fig. 2. These materials are consequently referred to hereafter as "nc steel".

It should be emphasized that in both cases only superficial layers are concerned by the microstructural changes. The
Table 1

Steel sheet properties.

\begin{tabular}{lll}
\hline Type of steel & Yield stress (MPa) & Strain to failure (\%) \\
\hline Coarse-grained & 280 & 70 \\
nt-ufc & 840 & 30 \\
nc & 920 & 20 \\
\hline
\end{tabular}

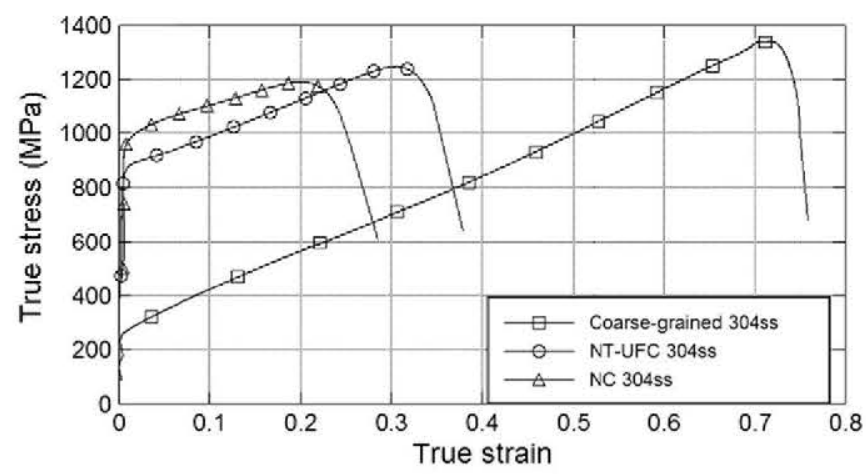

Fig. 3. Quasi-static uniaxial tension stress strain curves for coarsegrained, nt-ufe and ne steel samples.

notation "nt-ufc" and "nc" consequently do not refer to bulk materials, but rather to the surfaces of the plates.

A series of uniaxial tension tests was performed on dogbone-shaped samples $4 \mathrm{~cm}$ long, $0.5 \mathrm{~cm}$ wide (in the central section) and $1 \mathrm{~mm}$ thick. The quasi-static properties of the three different steels are shown in Table 1. The corresponding stress-strain curves for all samples are shown in Fig. 3.

High-strain-rate tensile tests were also performed on a Hopkinson split bar, at strain rates of $500-1000 \mathrm{~s}^{-1}$. The results are shown in Fig. 4.

It can be noted that the high-strain-rate results for nt-ufc and nc samples are very similar, with a moderate increase of the yield stress from $840 \mathrm{MPa}$ and $920 \mathrm{MPa}$ (in the quasistatic case), respectively, to $1 \mathrm{GPa}$. For the coarse-grained samples, the yield stress was increased more significantly from $280 \mathrm{MPa}$ to $450 \mathrm{MPa}$.

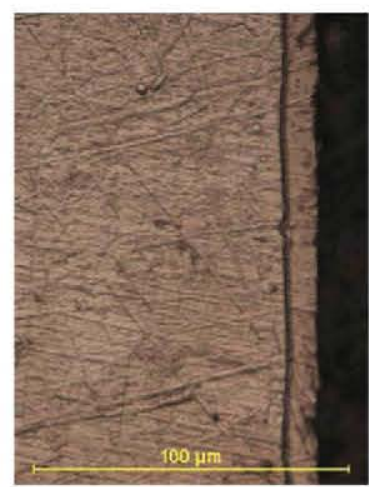

(a)

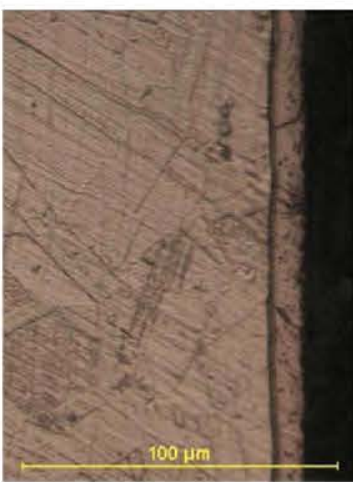

(b)

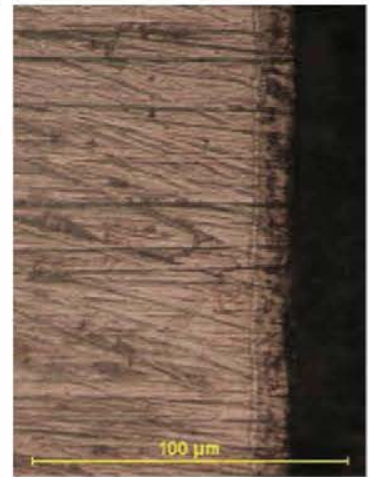

(c)

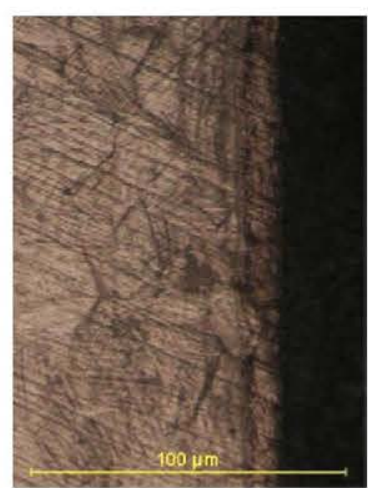

(d)

Fig. 2. Cross-sectional optical micrographs of the (a) un-SMAT, (b) $1 \mathrm{~min}$, (c) 4 min and (d) 15 min SMAT 304 stainless steel samples after plasma nitriding. 


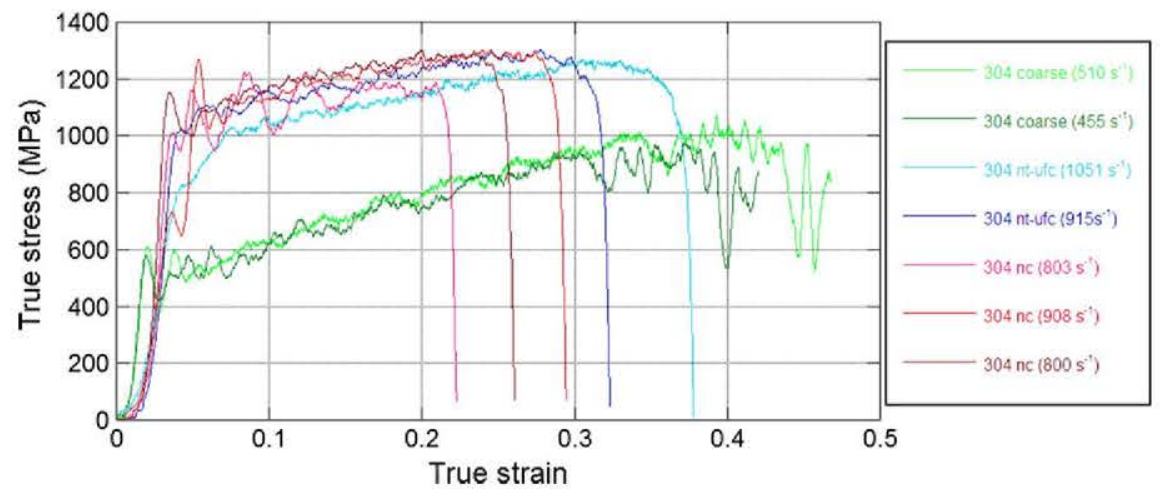

Fig. 4. High-strain-rate stress-strain curves for coarse-grained, nt-ufc and nc steel samples.

Table 2

Sample series: composition and thickness.

\begin{tabular}{rllll}
\hline Series & Material 1 & Thickness 1 & Material 2 & Thickness 2 \\
\hline 1 & $304 \mathrm{ss}$ & $1 \mathrm{~mm}$ & - & - \\
2 & $304 \mathrm{ss}$ & $1 \mathrm{~mm}$ & Hexply 8552 & $2 \mathrm{~mm}$ (10 layers) \\
3 & - & - & Hexply 8552 & $2 \mathrm{~mm}$ (10 layers) \\
4 & 304 SMAT (nt-ufc) & $1 \mathrm{~mm}$ & - & - \\
5 & 304 SMAT + Nitriding (nc) & $1 \mathrm{~mm}$ & - & - \\
6 & 304 SMAT (nt-ufc) & $1 \mathrm{~mm}$ & Hexply 8552 & $2 \mathrm{~mm}(10$ layers) \\
7 & 304 SMAT + Nitriding (nc) & $1 \mathrm{~mm}$ & Hexply 8552 & $2 \mathrm{~mm}(10$ layers) \\
8 & 304ss & $1 \mathrm{~mm}$ & Hexply 8552 & $4 \mathrm{~mm}(20$ layers) \\
9 & 304 SMAT (nt-ufc) & $1 \mathrm{~mm}$ & Hexply 8552 & $4 \mathrm{~mm}(20$ layers) \\
10 & 304 SMAT + Nitriding $(\mathrm{nc})$ & $1 \mathrm{~mm}$ & Hexply 8552 & $4 \mathrm{~mm}$ (20 layers) \\
\hline
\end{tabular}

\subsection{Composites amd hybrids}

The hybrid plates were processed by combining $1 \mathrm{~mm}$ thick steel plates with composite plates. The latter were processed from preimpregnated unidirectional fiber layers (Hexcel 8552 AS4UD), attached to the steel plates and cured in a hot-plate press (LabPro 400). The configuration of each fiber layer is $0^{\circ} / 90^{\circ}$ with central symmetry. Two series of composite plates were made: one with 10 layers $(2 \mathrm{~mm})$ and another with 20 layers $(4 \mathrm{~mm})$.

Table 2 shows all the sample/test series as well as their configuration as used in the impact tests. All the samples were cut to a $50 \times 50 \mathrm{~mm}$ size.

Note that the sample thickness can be slightly smaller or larger due to SMAT procedure and/or resin flow within the press.

Each series of hybrid samples is tested with impacts on both composite and steel sides, to determine the optimal configuration. In the following, we indicate the series number (1-10) with the letter " $A$ " for steel-side impact samples and "B" for composite-side impact samples.

\section{Experimental ballistic campaign}

\subsection{Experimental set-up}

All the ballistic tests were made using a Sabre Ballistics air/helium-propelled gas gun firing $5.55 \mathrm{~mm}$ tempered steel spherical projectiles inside an impact chamber. The tempered steel is hard enough to avoid deformation of the projectile, and its energy absorption can thus be neglected. The impacts were recorded with a Phantom high-speed camera. Image-processing software allowed the incident and residual velocities to be measured, using the time interval between frames $(1 / 30,000 \mathrm{~s})$ and a reference length (plate length, projectile diameter, etc.).

The ballistic limit of the materials, defined as the maximum velocity at which the material is not completely perforated (or is perforated with zero exit velocity), was then extracted from these results. Note that an equivalent statistical definition of the ballistic limit uses the notation " $V_{50}$ ", as the velocity for which $50 \%$ of projectiles are stopped and $50 \%$ go through the plate.

Using the velocity measurements and the weight of the projectile, the incident and residual (in case of perforation) kinetic energies are easily calculated; the difference being the energy absorbed by the plate.

\subsection{Test results}

In the following, the ballistic performance for the steelalone plates is presented, followed by a study on the sequencing steel-composites vs. composites-steel for coarse-grained steel hybrids, on the performance of $\mathrm{nc} /$ nt-ufc hybrids and on 20-layer composite hybrids. Note that videos of experimental tests exhibiting the different fracture modes for the different configurations are available as Supplementary materials. 


\subsubsection{Coarse-grained steel vs. $n t-u f c l n c$ steel}

The first series of tests with $1 \mathrm{~mm}$ thick AISI 304 steel plates showed different failure modes for different impact velocities, see Figs. 5-7. The transition between each one of them is directly related to the amount of plastic deformation achieved by the plate upon impact. Before perforation, deformation rises with impact velocity, reaching a maximum at the ballistic limit $\left(350-357 \mathrm{~m} \mathrm{~s}^{-1}\right)$, just before the failure of the plate. At velocities just above the ballistic limit, the failure mode is called "plastic dishing" (Fig. 5), followed by "shear plugging" (Fig. 6) as velocity increases further. At very high velocity, the deformation around the hole decreases, to a point where very little deformation is observed, but with fragmentation of the ejected plug $\left(570-625 \mathrm{~m} \mathrm{~s}^{-1}\right)$.

The test results, plotted as the residual velocity $V_{r}$ vs. incident velocity $V_{0}$ in Fig. 8, for the nt-ufc and nc $1 \mathrm{~mm}$ thick plates, showed a similar behavior as for the coarse-grained 304 steel at high velocities, but below $400-450 \mathrm{~m} \mathrm{~s}^{-1}$ the results diverge with a lower energy absorption. This range corresponds to the same velocity range at which the coarse-grained steel shifted from plugging failure to dishing failure. Nt-ufc and nc steels still exhibit a shear plugging failure with very low deformation, even at the lowest velocity attainable in the gas gun $\left(\simeq 300 \mathrm{~m} \mathrm{~s}^{-1}\right)$.

\subsubsection{Coarse-grained hybrid plates}

The effect of the $2 \mathrm{~mm}$ composite layer added to the steel is an obvious increase in ballistic limit and energy absorption. However, a difference can a priori be expected depending on the impact side. The samples experimentally impacted on the composite side were found to present a higher-energy absorption than those impacted on steel side, see Fig. 9. The analysis of these samples shows a wider deformed circular area around the exit hole in the back

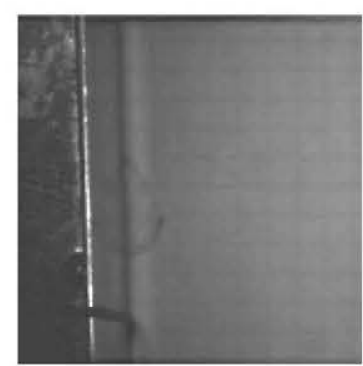

(a) $t_{0}$

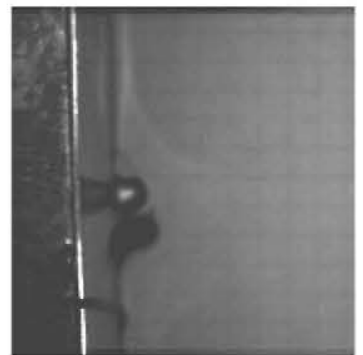

(b) $t_{0}+66.64 \mu \mathrm{s}$

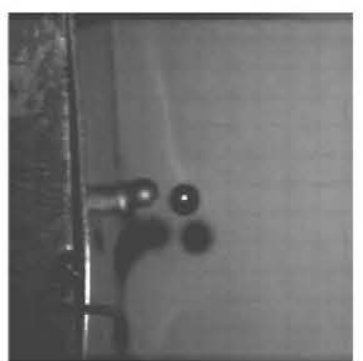

(c) $t_{0}+133.28 \mu \mathrm{s}$

Fig. 5. "Dishing" failure in a $1 \mathrm{~mm}$ AISI $304 \mathrm{ss}$ steel plate, impacted at $360 \mathrm{~m} \mathrm{~s}^{-1}$, just above the ballistic limit $\left(\sim 355 \mathrm{~m} \mathrm{~s}^{-1}\right)$, with a residual velocity of $100 \mathrm{~m} \mathrm{~s}^{-1} ; t_{0}$ corresponds to the impact time.

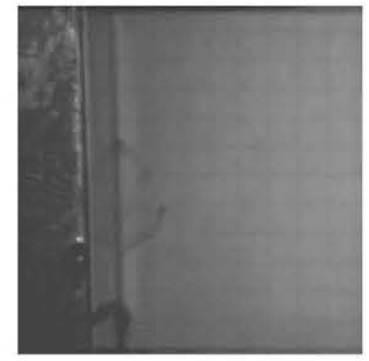

(a) $t_{0}$

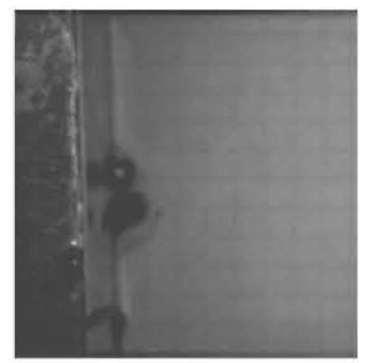

(b) $t_{0}+33.32 \mu s$

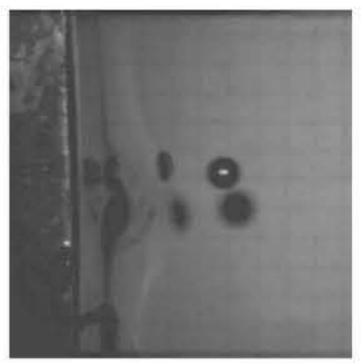

(c) $t_{0}+133.28 \mu \mathrm{s}$

Fig. 6. "Plugging" failure in a $1 \mathrm{~mm}$ AISI $304 \mathrm{ss}$ steel plate, impacted at $385 \mathrm{~m} \mathrm{~s}^{-1}$ with a residual velocity of $200 \mathrm{~m} \mathrm{~s}^{-1}$; $t_{0}$ corresponds to the impact time.

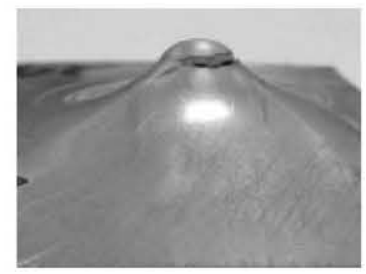

(a) First crack

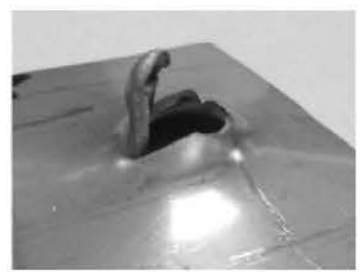

(b) "Dishing" fracture

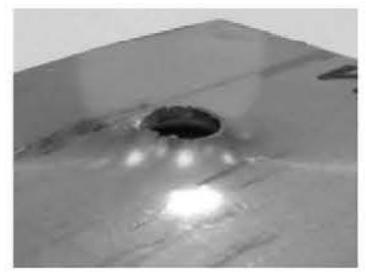

(c) "Plugging" fracture

Fig. 7. Different failure and deformation modes in the AISI 304ss for different impact velocities. 


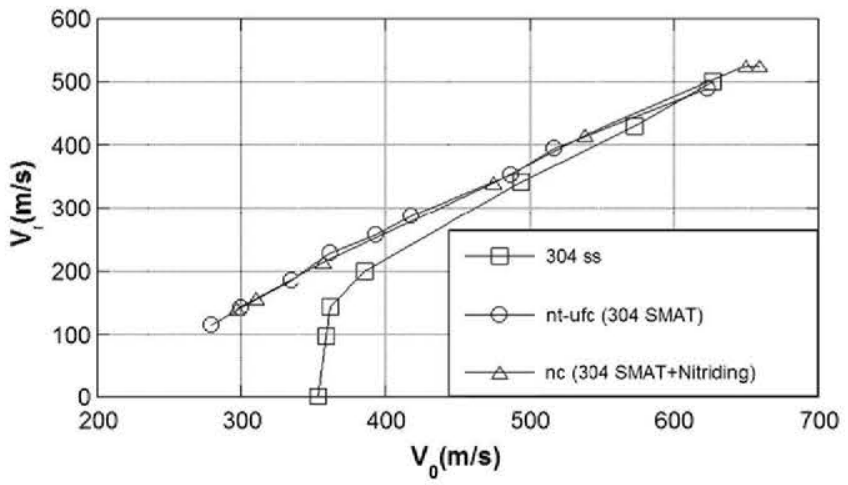

Fig. 8. Test results for $1 \mathrm{~mm}$ thick steel plates (series 1,4 and 5, see Table 2).

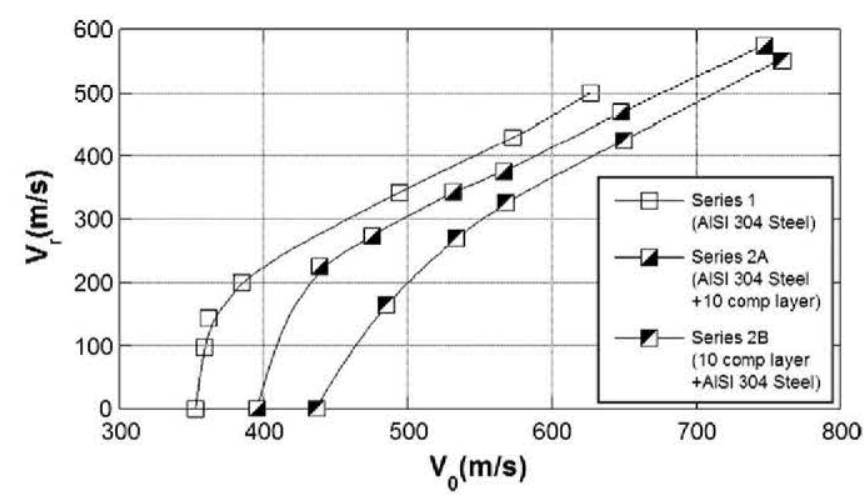

Fig. 9. Test results for a $1 \mathrm{~mm}$ thick coarse-grained steel plate and 10 layer composite-steel hybrid, impacted on both steel (A) and composite (B) sides.

steel plate, with a different failure mode, "petalling". When this failure takes place, a star-shaped tear appears after plastic elongation, see Fig. 10. Note that the maximum deformation before failure, measured in the direction of impact, is roughly the same as in non-hybrid steel plates.
In the samples impacted on the composite side, the composite plate detaches from the steel plate. When impacted on the steel side, this only happens at very low velocities where the deformation of the steel plate is very high. This suggests that impacts on the steel side result in very local stress concentration, whereas impacts on composite side disperse the force over a wider surface, thus detaching the material interface. Note that the cohesive energy dissipated during the detachments is commonly expected to remain minimal when compared to the plate absorption energy and the projectile incident/exit kinetic energy.

The failure mode of the composites in both cases is laminate crushing and shear fracture of fibers. As the behavior of steel is the focus of this paper, the composite failure modes will not be further studied here.

\subsubsection{Nt-ufc and nc hybrids}

Similarly to coarse-grained hybrids, a higher energy absorption for nt-ufc and nc hybrids was observed when impacted on the composite side. Based on this, the subsequent hybrid impacts are done on the composite side exclusively.

The 10-layer composite hybrids ( $2 \mathrm{~mm}$ thick) made with nt-ufc and nc steels exhibited a lower energy absorption than coarse-grained hybrids, see Fig. 11. Additionally, the nt-ufc and nc hybrids exhibit low deformation (measured in the direction of the impact), see Fig. 12. Note that no significant difference was observed between nt-ufc and nc hybrids.

\subsubsection{0-Layer composite hybrids}

As can be seen in Fig. 11, 20-layer composite ( $4 \mathrm{~mm}$ thick) hybrids show a higher energy absorption and ballistic limit than their 10-layer counterparts, but the coarse-grained hybrids still exhibit a better energy absorption than the ntufc and nc hybrids. All samples showed a wider extension of the deformation around the impact area than with 10 layers. For all steel types, the maximum deformation measured

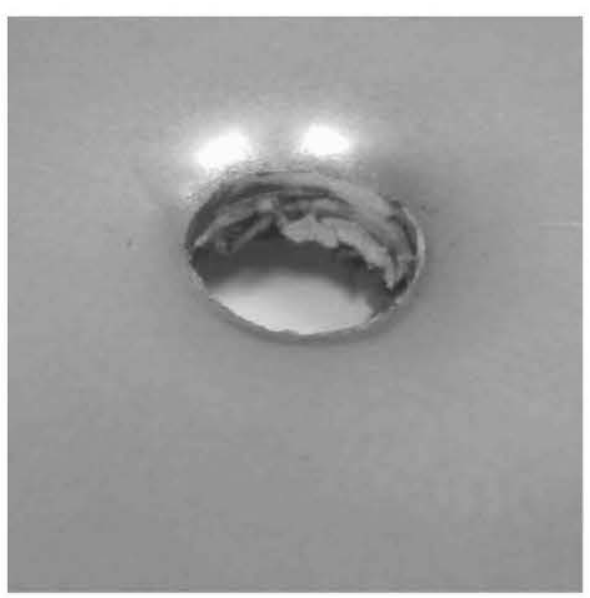

(A) Impact on steel side

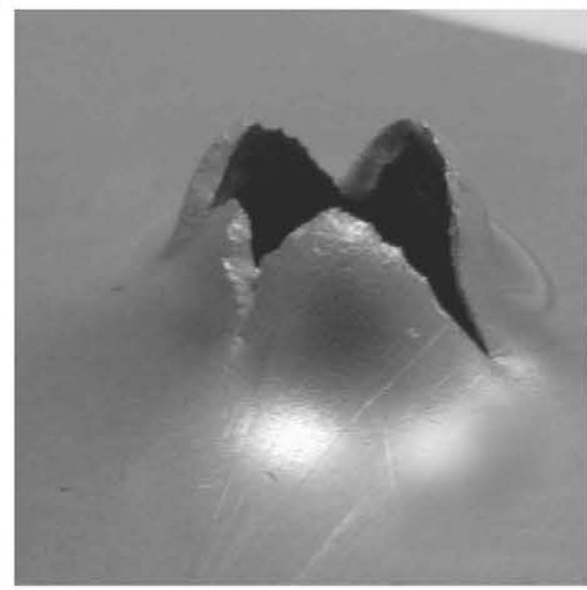

(B) Impact on composite side

Fig. 10. Typical failure modes in the steel plate, when placed on the impact side (A) or rear side (B) of the hybrid plate. 


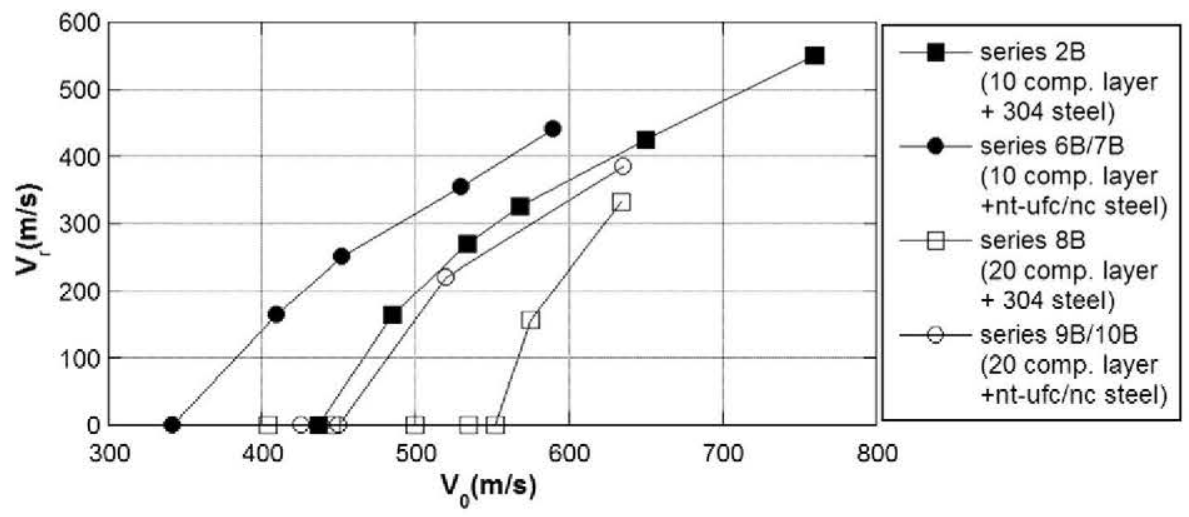

Fig. 11. Test results for 10- and 20-layer hybrids (coarse-grained, nt-ufe and nc) impacted on the composite side.

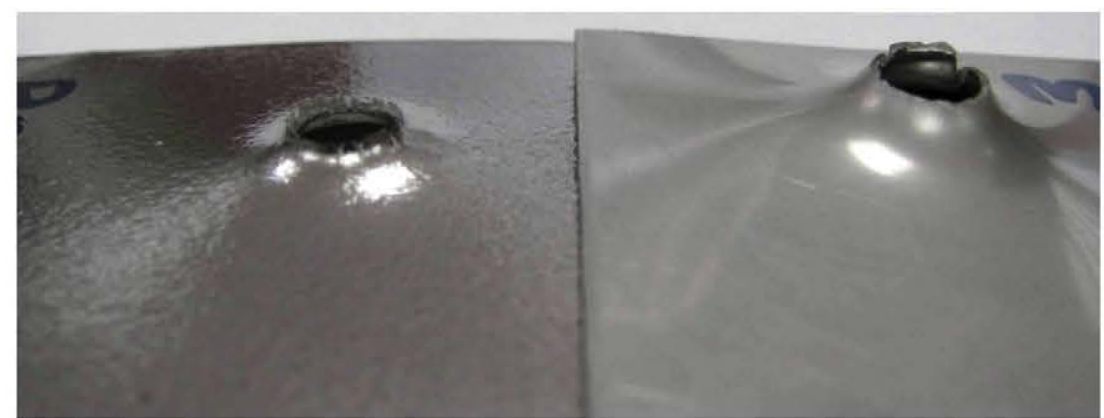

(a) nt-ufc (left) vs. coarse-grained $1 \mathrm{~mm}$ steel plates (right)

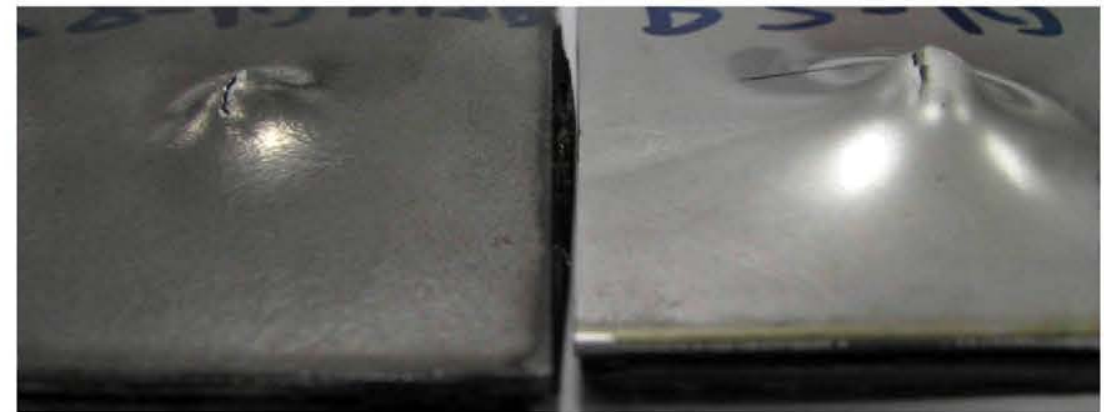

(b) nc hybrid (left) vs. coarse-grained hybrid (right)

Fig. 12. Reduced deformation in nt-ufe and ne steel plates, and hybrids, when compared with coarse-grained steel impacted at the same velocity; note that no significant difference was observed between nt-ufc and nc hybrids.

in the direction of the impact is roughly the same as with 10 layers of composite, or without composite.

\section{Numerical simulation}

The similar behavior of the nt-ufc and nc samples on the one hand, and the lower apparent performance of the nt$\mathrm{ufc} / \mathrm{nc}$ samples with respect to coarse-grained samples (hybrid or not) on the other hand, is somehow puzzling, especially in view of their superior uniaxial lower rate performances see Section 2.1. To better understand the intrinsic deformation mechanisms leading to these a priori contradictory results, finite-element simulations of the ballistic tests are developed in this section, and the results are compared to the experimental tests.

\subsection{Model description}

Ballistic impacts in metals involve many different deformation mechanisms characterized by a combination of large deformation (strain rate) hardening and interaction between different damage mechanisms [47]. Although computational simulations of impact necessarily imply severe non-linearities, a good understanding of the deformation patterns can generally be achieved, at least up until failure.

\subsubsection{Plastic deformation}

To address the response of structure to high-velocity impact, appropriate constitutive relations are required that cover the stress-strain behavior, strain-rate dependence and even temperature sensitivity. For most metals, it is well 
understood that a (small deformation) rate-dependent plastic form can be used with the assumption of isotropic hardening. The elastic deformation is defined by the Young's modulus $E$ and the Poisson's ratio $v$. A group of phenomenological and theoretical models were proposed with different degrees of complexity [59,60]. Among these models, the one proposed by Johnson and Cook focused on structures subjected to high-strain-rate deformation which can be characterized by the yield stress $\sigma_{y}$ analytical form (2) [61]:

$\sigma_{y}=\left[A+B\left(\bar{\epsilon}_{p l}\right)^{n}\right]\left[1+C \ln \left(\frac{\dot{\bar{\epsilon}}_{p}}{\dot{\epsilon}_{0}}\right)\right]\left(1-\hat{\theta}^{m}\right)$

where $A, B, C, \dot{\epsilon_{0}}, m$ and $n$ are model parameters, $\bar{\epsilon}_{p}$ and $\hat{\theta}$ are respectively the equivalent plastic strain and an nondimensional linearly temperature-dependent parameter accounting for the transition from the reference state to the melting state. Many studies have confirmed the good agreement of this model with experiments $[62,63]$, and its suitability to capture the main deformation features of metals under dynamic loading conditions. An additional advantage stems from the usual ease for determining the model parameters from laboratory tests. In the model used here, the temperature rise was not considered as a first approximation, and $\hat{\theta}$ was taken constant and equal to 0 .

The results from the quasi-static and Hopkinson bar high-strain-rate tests for the three materials (Fig. 4) are used for the calibration of this model. The calibration was done analytically by noting that under uniaxial deformation, equivalent plastic strain and von Mises stress are simply the axial plastic strain and axial stress, respectively. Typical values for the density $\rho$, Young's modulus $E$ and Poisson's ratio $v$ for steel were also used. The final model parameters are given in Table 3, and the corresponding calibrated stress -strain curves in Figs. 13 and 14.

It should be emphasized that the calibrated parameters allow for a very good fit of the high-strain-rate data, with a more approximate match in the case of quasi-static tests. A simultaneous exact fit of both sets of curves was found to be impossible, due to the simplicity of the model itself. However, in the subsequent ballistic tests involving highstrain-rate deformation, the calibration achieved here, favoring the fit with the high strain rate, was judged sufficient.

\subsubsection{Damage}

Coupled with the above constitutive relation, a failure criterion is required to characterize the material properties degradation due to penetration and perforation. Hancock

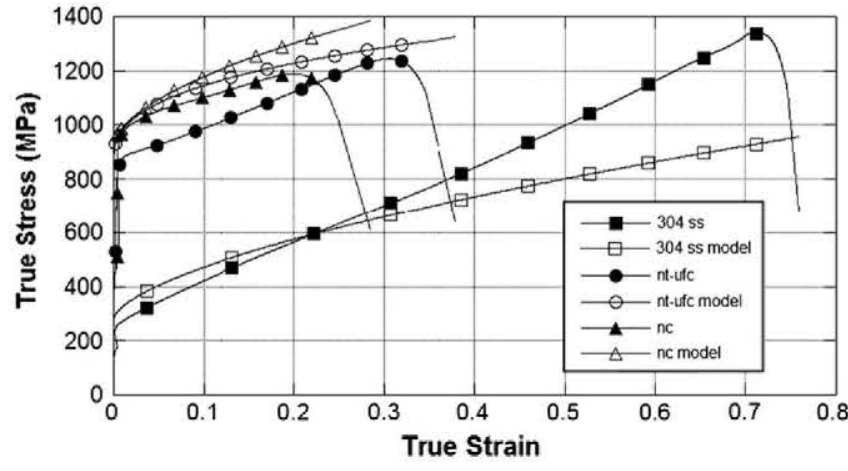

Fig. 13. Calibrated Johnson-Cook model vs. quasistatic test results.

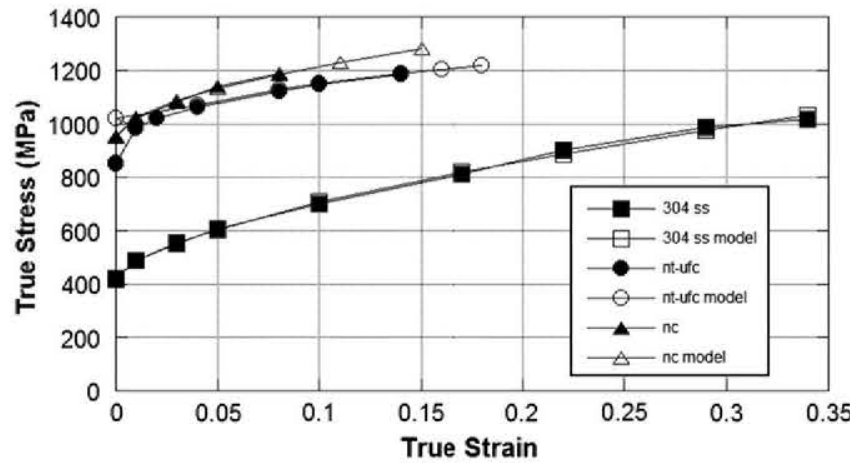

Fig. 14. Calibrated Johnson-Cook model vs. high-strain-rate test results

and Mackenzie accounted for material failure with a relation covering stress state and void growth [64]. Johnson and Cook further developed this form by taking the strain rate and thermal dependence into consideration [59]. As the impact on ductile metal is reliably predicted by the accumulated equivalent plastic strain, the Johnson-Cook failure model based on the plastic strain was used. In this model, failure occurs when the parameter $D$ defined by

$D=\int \frac{1}{\epsilon_{f}} d \bar{\epsilon}_{p}$

reaches a value of 1 . In this expression, the equivalent strain to fracture $\epsilon_{f}$ is defined by [59]:

$\epsilon_{f}=\left(d_{1}+d_{2} e^{-d_{3} \frac{p}{\sigma}}\right)\left[1+d_{4} \ln \left(\frac{\dot{\bar{\epsilon}}_{p}}{\dot{\epsilon}_{0}}\right)\right]\left(1+d_{5} T\right)$

where $d_{1}$ to $d_{5}$ are material constants, which can be determined from experiments, $p$ is the hydrostatic pressure, i.e. the third of the trace of the Cauchy stress tensor, $\sigma$ is the von Mises stress, and $T$ is the temperature.

Table 3

Model parameters.

\begin{tabular}{llllllll}
\hline & $\rho$ & $E\left(\mathrm{~kg} \mathrm{~m}^{-3}\right)$ & $v(\mathrm{GPa})$ & $A$ & $B$ & $C$ \\
\hline 304 ss & 8000 & 207.8 & 0.3 & 280 & 802.5 & 0.0799 \\
304 nt-ufc & 8000 & 207.8 & 0.3 & 850 & 668.5 & 0.0004 \\
304 nc & 8000 & 207.8 & 0.3 & 950 & 941 & 0.622 \\
\hline
\end{tabular}


Table 4

Material models for the Johnson-Cook damage model.

\begin{tabular}{lll}
\hline & $d_{1}$ & $d_{4}$ \\
\hline 304 ss & 0.69 & 0.0546 \\
304 nt-ufc & 0.30 & 0.0039 \\
304 nc & 0.20 & 0.0042 \\
\hline
\end{tabular}

Assuming that the loading states do not change too abruptly during deformation, one can assume that $d_{2}=d_{3}=d_{5}=0$ as a first approximation [65]. For the three materials, the constants obtained from the strain-to-failure in the high-strain-rate tests are shown in Table 4.

\subsubsection{Finite-element set-up}

The software Abaqus/Explicit was used for the simulations [66]. The steel plates were discretized with 96,202 reduced integration linear brick elements (C3D8R) and 434 linear wedge elements (C3D6). The previously defined constitutive model is used for the steel plates. The sensitivity of the predicted results to mesh refinement was a key concern during the simulation, and hence the mesh involved in the region beneath the impact site was adequately refined, see Fig. 16.

The projectile was modeled as an elastic ball with the same density, a slightly higher Young's modulus $(210 \mathrm{GPa})$ and the same Poisson's ratio as the plates, but without plasticity.

The plate elements beneath the impact site meeting the failure criterion are subsequently removed from the model. Note that such approach violates the conservation of mass, but under the assumption that the fractured elements are actually ejected on the other side of the plate, it is not expected to change the physics of the problem within the plate. Accordingly, a node-based slave-contact surface containing the plate nodes within the impact zone and an element-based master-contact surface containing the whole projectile were defined in the simulation. The plate was left unconstrained, as in the experiments, while the projectile was only constrained to eliminate its rigid body rotation.

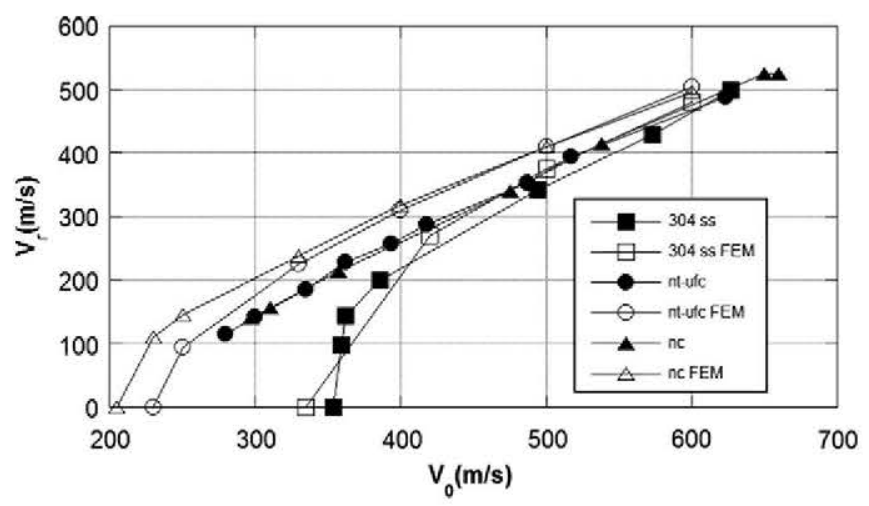

Fig. 15. Comparison of the ballistic impact test between finite-element results and experimental data (Fig. 8).

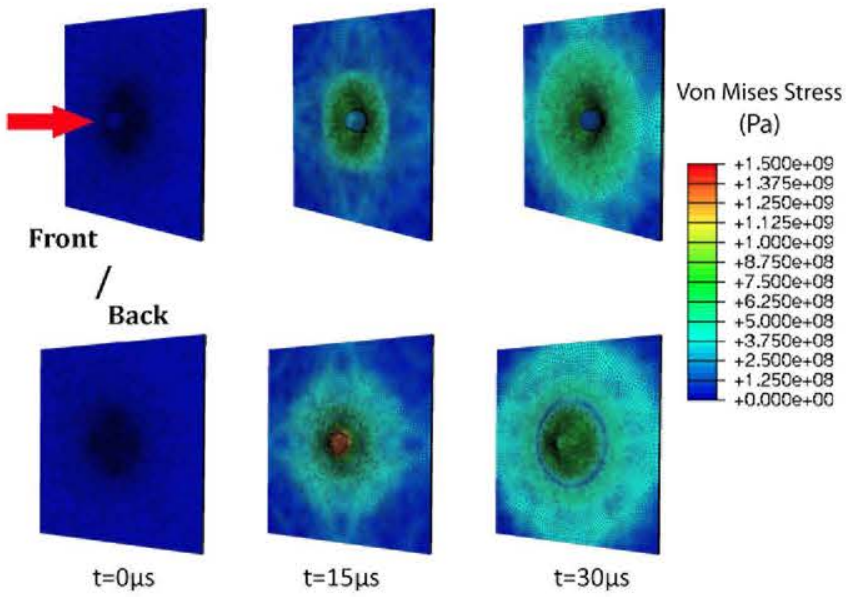

Fig. 16. Front and back coarse-grained steel plate von Mises stress fields, when subjected to a $330 \mathrm{~m} \mathrm{~s}^{-1}$ projectile at $t=0,15,30 \mu \mathrm{s}$.

\subsection{Simulation results}

The impact residual velocity predictions made by the model fit the test results with good accuracy, see Fig. 15. Additionally, the ballistic limits for the nt-ufe and ne plates are numerically predicted to be 235 and $205 \mathrm{~m} \mathrm{~s}^{-1}$ (indeed lying below the gas gun limits).

The time history von Mises stress fields for the coarsegrained steel at $330 \mathrm{~m} \mathrm{~s}^{-1}$ impact velocity is shown in Fig. 16.

\section{Analysis of results}

In this section, the test results are analyzed with a special emphasis on the similarity between nt-ufc and nc, the rationalization of their lower energy absorbtion, the composite layer relevance and the overall smaller nt-ufc/nc deformation. The simulations of Section 4.2 are used throughout this analysis to support the different assertions made.

\subsection{Similar behavior of $n t-u f c$ and $n c$ steel}

The first observation is the similar ballistic behavior of the nt-ufc and nc plates. This was originally suggested by Fig. 8 and has been observed in all subsequent hybrid tests. This result is a priori surprising considering the relative ductility difference observed in Figs. 3 and 4 under uniaxial loading. It is even more puzzling in light of the very low ductility dependency on strain rate observed in nt-ufc [26], thus implying that the nt-ufc curve in Fig. 8 should a priori be positioned to the right of the nc curve.

This result can be partially explained by the samples' homogeneity, which differs only in the nature of the outermost layers (where the nitriding is applied). Another possibility can be related to the fact that uniaxial deformation involves intuitively more volumetric (hydrostatic) deformation than deviatoric (shear) when compared to impact deformation. To investigate this possibility, the simulated von Mises stress and pressure are plotted in Fig. 17 for 


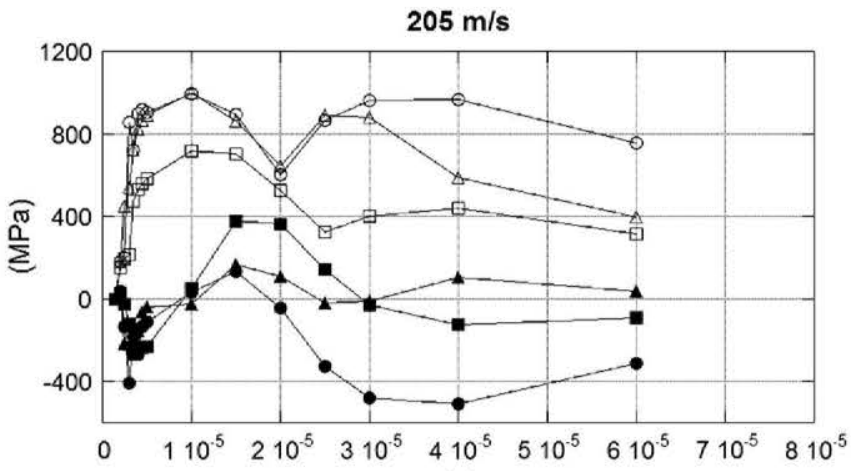

(s)

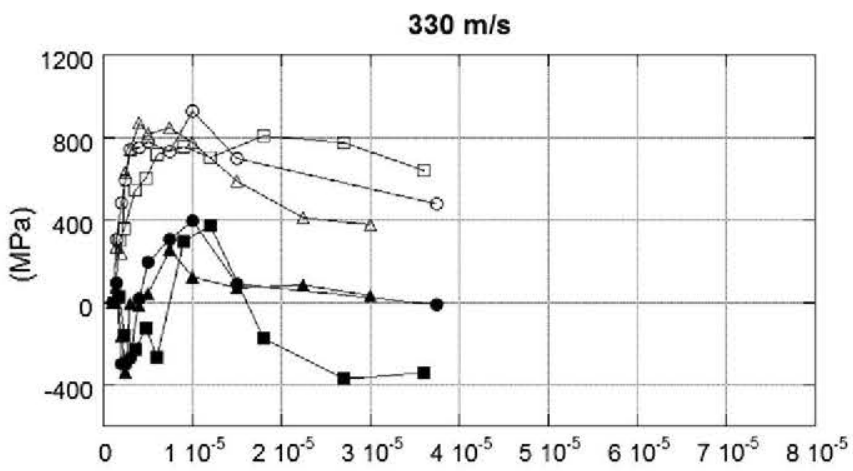

(s)

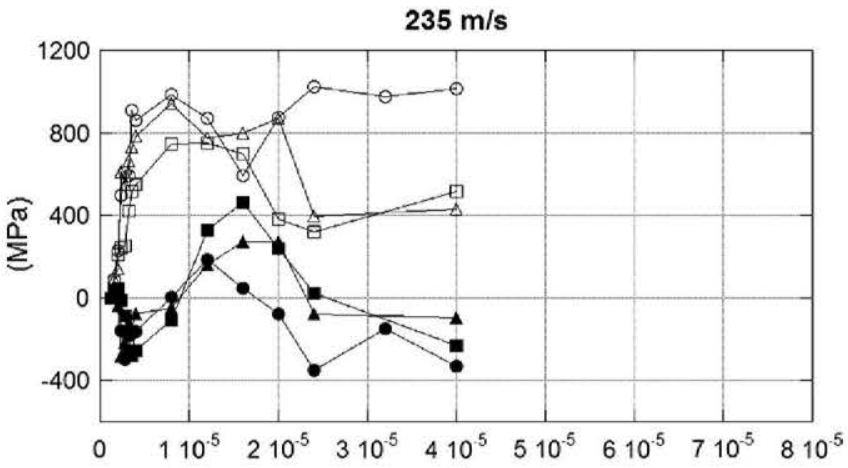

(s)

Average of 5 points
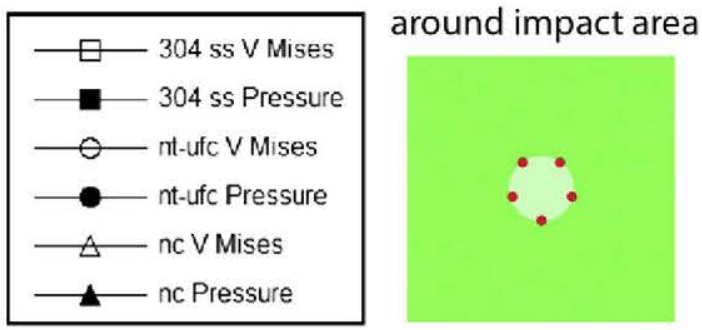

Fig. 17. Averaged simulated von Mises stress and pressure evolution in the periphery of the projectile during impact for a projectile velocity of $V_{50}-5 \mathrm{~m} \mathrm{~s}^{-1}$ for the ballistic limit $V_{50}$ of all three steels.

the average value measured in the area surrounding the projectile periphery (at $3 \mathrm{~mm}$ from the center) for three projectile velocities taken at $\sim 5 \mathrm{~m} \mathrm{~s}^{-1}$ below the simulated ballistic limits of all three steels. Note that this circumferential region is approximately the one where facture first occurs in all three modes (see Fig. 7). In the simulation pictures, the high concentration of stress appears as a circular area around the projectile which coincides with the fracture in the experiments, see Fig. 16.

Additional tensile uniaxial quasi-static finite-element simulations were done, and the pressure and von Mises stress evolutions in the middle of the samples (where the fracture takes place) are plotted in Fig. 18.
As can be seen in both series of graphs, the stress triaxiality (the ratio of the pressure to the von Mises stress) in both problems is radically different. Whereas Fig. 18 exhibits a stress triaxiality constant of roughly $1 / 3$, it rapidly oscillates in Fig. 17 between roughly $-1 / 2$ and 1/2, eventually converging to 0 (at a slower pace for coarse-grained steel, as could be expected from its higher ballistic limit). This observation implies that what is potentially at the source of the higher ductility of nt-ufc in uniaxial deformation, i.e. the higher coherence of the twin boundaries when compared to nc grain boundaries [7], is intrinsically dependent on the steadiness of the volumetric contribution of the stress. This explanation is rationalized by the fact that

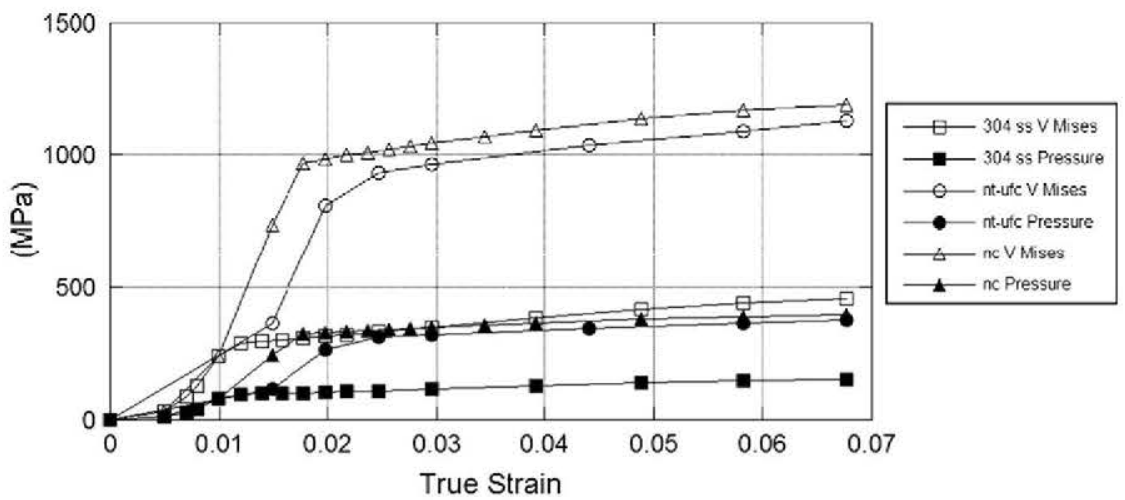

Fig. 18. Simulated von Mises stress and pressure evolution in the sample center during quasi-static uniaxial tension. 
shearing (oscillations) would naturally tend to alter the coherence of the twin boundaries in a more effective way than pure hydrostatic pressure would, thus decreasing drastically the ductility improvement expected in nt-ufc, and providing a possible explanation for the similar behavior of nc and nt-ufc under ballistic conditions.

\subsection{Lower energy absorption of $n t-u f c$ and $n c$ steel}

Another noteworthy point is the lower energy absorption of both nt-ufc and nc steels, when compared to coarse-grained steel. Plastic deformation is one of the principal energy-absorption mechanisms in steels, but in those materials the shear plugging mechanism results in very little deformation. The tendency to shear plugging increases with plate hardness [33] as measured by the yield strength or Brinell hardness number (very high in the case of nitriding nc steel). It must also be emphasized that thin plates have a greater tendency to plug, and this is increased with velocity and bluntness of the projectiles [33]. In a hard plate, the radial pushing of the material becomes more difficult, and narrow shear area builds up surrounding the projectile, as confirmed by the triaxiality in Fig. 17. All of these reasons consequently explain the observed shear plugging failure. However, this does not provide any direct answer to the lower energy absorption.

This a priori counterintuitive effect can be rationalized in a similar way as in the previous discussion. The high yield strength of nt-ufc and nc steels are related to the dislocation blocking action of twin boundaries and grain boundaries, respectively. From a mechanistic point of view, this leads to a lower hardening for nc/nt-ufc than for their coarse-grained counterpart. $\mathrm{Nc} / \mathrm{nt}$-ufc are thus more likely to be subjected to shear band/localized deformation, eventually leading to a lower energy absorption.

In Fig. 19, the absorption energies for coarse-grained, nc and nt-ufc steels are shown for (a) the quasi-static, and high-strain-rate tensile tests up to $20 \%$ strain (lower bound of the strains-to-failure) and until failure and (b) for the impact tests at different projectile incoming velocities.

For quasi-static tensile tests considered up to failure, coarse-grained metals absorb more energy because of their higher ductility. For the high-strain-rate cases, the higher strengths of nc/nt-ufc seem to balance their lower ductility and the energies are comparable. However, for a given strain before failure such as $20 \%$, nc/nt-ufc steels exhibit better energy absorption capabilities than coarse-grained steel, at both rates. On the contrary, impact energy absorption properties are consistently better for coarse-grained steels than for nc/nt-ufc at all projectile velocities. These results confirm the important role of the deformation triaxiality characteristics leading to either improvement or deterioration of properties when using nc/nt-ufc instead of coarse-grained metals. Based on the problem at hand, a preliminary conclusion can be made: volumetric-dominated deformation will benefit from the use of nc/nt-ufc,

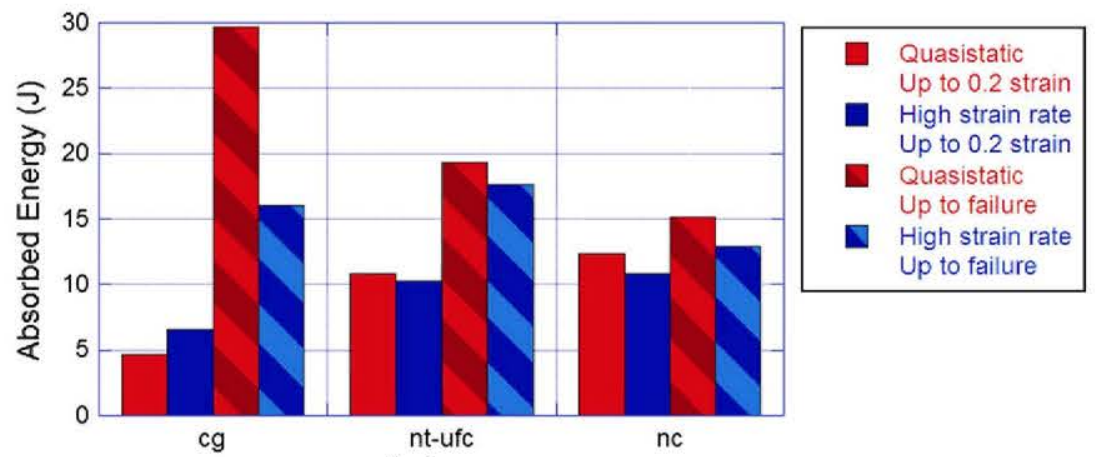

(a)

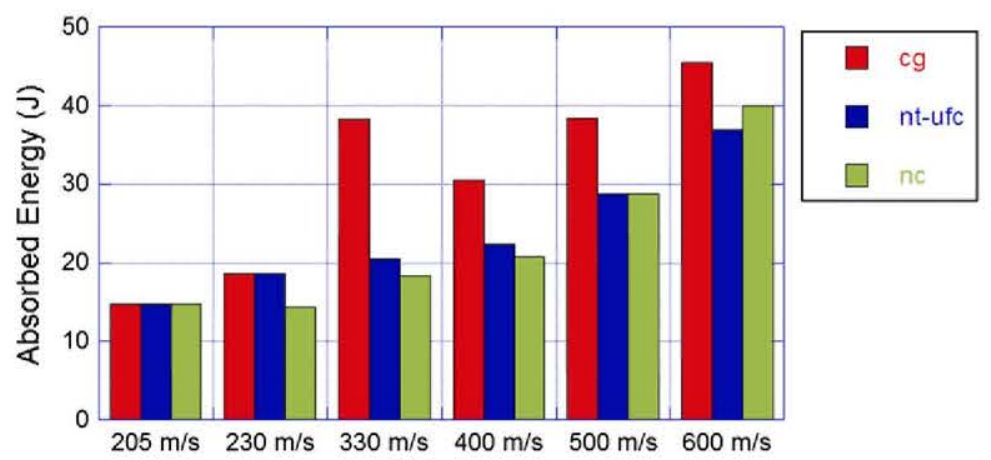

(b)

Fig. 19. Absorbed energy for coarse grained, nc and nt-ufc under (a) quasi-static, and high-strain-rate tensile tests up to $20 \%$ strain (lower bound of the strains-to-failure) and until failure and (b) impact tests at different projectile incoming velocities. 
Table 5

Experimental and simulated maximum deformation of the steel plates for each sample series prior to failure.

\begin{tabular}{lll}
\hline Series & Deformation $(\mathrm{mm})$ & \\
\cline { 2 - 3 } & Exp & Sim \\
\hline 1 & 6 & 5.93 \\
4 & - & 4.10 \\
5 & - & 3.61 \\
$2 \mathrm{~B}$ & 6 & - \\
$6 \mathrm{~B}, 7 \mathrm{~B}$ & 3.5 & - \\
$8 \mathrm{~B}$ & 6 & - \\
$9 \mathrm{~B}, 10 \mathrm{~B}$ & 3.5 & - \\
\hline
\end{tabular}

whereas coarse-grained metals will remain the best choice for deviatoric-dominated deformation. In the following, we will see that this conclusion does not always hold.

\subsection{Composite spreads shock}

A better performance can be achieved by placing a composite plate in front of the steel, as shown in Sections 3.2.3 and 3.2.4. The hybrids impacted on the steel side exhibit little interaction between both materials. On the other hand, the hybrids impacted on the composite side exhibit a higher energy absorption. The wider deformed surface and the fact that in perforated plates the hole is wider (in metalonly plates it was narrower, see Fig. 10) suggest that the composite helps to spread the shock. This, in turn, results in a less concentrated impact on the steel plate, and a wider area of steel is deformed: more energy is absorbed.

Based on the previous discussion, nc/nt-ufc steels are more likely to be subjected to shear bands/localized deformation. From a structural perspective, dislocations in nanocrystals or in between nanotwins are indeed confined to very small volumes. Under uniaxial deformation, plastic deformation mechanisms participate in a relatively homogeneous way within the sample, i.e. yielding is postponed by the overall action of all twin/grain boundaries, but all of them participate in the deformation. Under ballistic conditions, the deformation zone is very narrow and coarsegrained steel can thus accommodate the shearing in a more efficient way by letting dislocation travel in larger volumes.
Table 6

Experimental deformation of the different steels in hybrid plates impacted at the same velocity $\sim 450 \mathrm{~m} \mathrm{~s}^{-1}$.

\begin{tabular}{ll}
\hline Series & Deformation $(\mathrm{mm})$ \\
\hline $8 \mathrm{~B}$ & $5-5.5$ \\
$9 \mathrm{~B}, 10 \mathrm{~B}$ & 3.5 \\
\hline
\end{tabular}

$\mathrm{Nc}$ and nt-ufc steels, on the contrary, constrain dislocations to remain in small volumes. In summary, under ballistic loading conditions, dislocations are confined locally in nc/nt-ufc steels. Based on this analysis, adding composite layers in front of $\mathrm{nc} / \mathrm{nt}$-ufc steels can consequently be an adequate way to avoid local shearing of the material (low stress triaxiality), thus leveraging the benefits of nc and nt-ufc. Adding a thicker composite plate naturally increases the performance (Fig. 11), and further studies will aim at determining the optimum composite layer thickness such that the ballistic limit of a nt-ufc/nc hybrid becomes higher than that of its coarse-grained hybrid counterpart. Note finally that this analysis is confirmed by the change in failure mechanism in the composites-first hybrids to petalling, both for coarse-grained steel and nc/nt-ufc (instead of plugging for the latter).

\subsection{Lower deformation}

The experimental maximum deformations of the steel plates for each sample series, just prior to failure (impact velocity just below $V_{50}$ ) and measured in the impact direction are shown in Table 5. The simulated deformations under the same conditions for the metal-only plates are also presented.

From these results, it appears that lower deformations are observed in nt-ufc and nc steel prior to perforation, when compared to coarse-grained steel impacted at a velocity below its own ballistic limit. Additionally, the maximum deformation for a given steel just before the ballistic limit is independent of the configuration, i.e. whether there is a composite layer or not. Based on this observation, the simulated values for series 1,4 and 5 can be compared directly

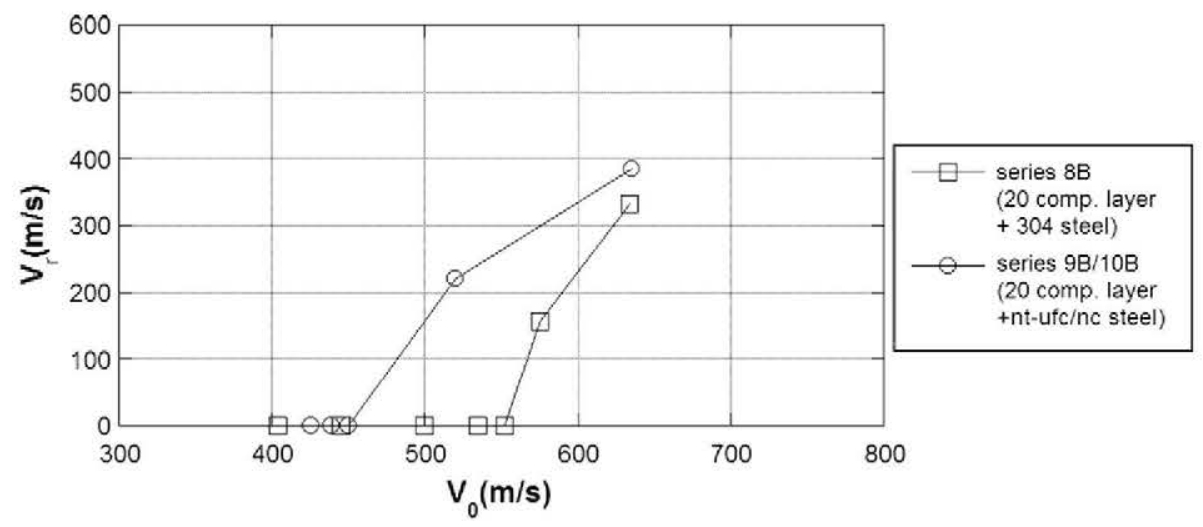

Fig. 20. Comparison between coarse-grained and nanocrystalline hybrids of the same weight. 


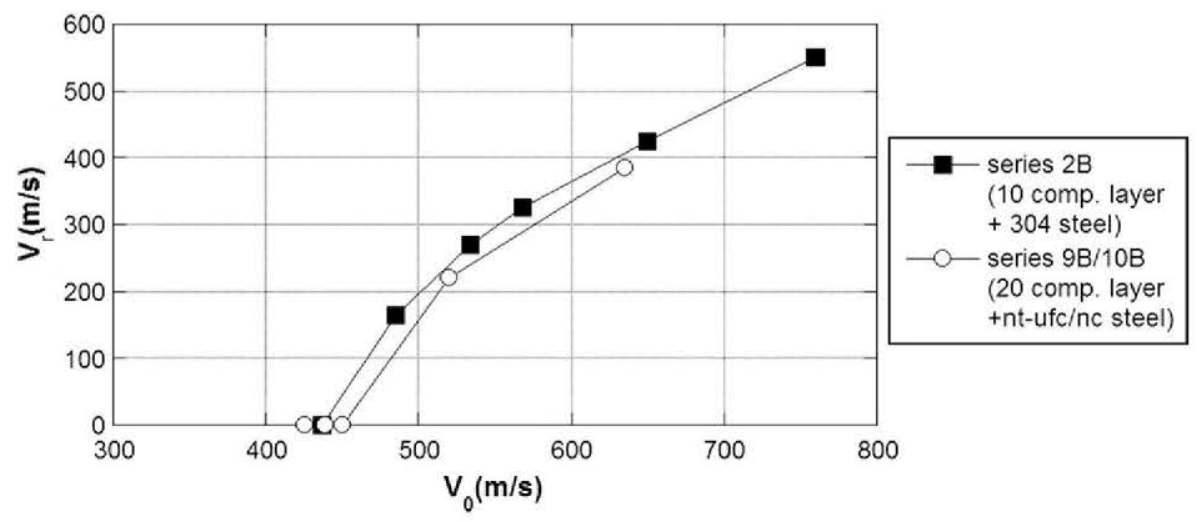

Fig. 21. Comparison between coarse-grained and nanocrystalline hybrids of the same ballistic limit.

Table 7

Perforation energy normalized per areal density.

\begin{tabular}{lllll}
\hline Series & $V_{50}\left(\mathrm{~m} \mathrm{~s}^{-1}\right)$ & Energy $(\mathbf{J})$ & Areal density $\left(\mathrm{kg} \mathrm{m}^{-2}\right)$ & Energy/areal density $\left(\mathrm{J} \mathrm{m}^{-2} \mathrm{~kg}^{-1}\right)$ \\
\hline 1 & 350 & 43 & 8 & 5.38 \\
2A & 400 & 56.2 & 11.16 & 5.04 \\
2B & 440 & 68 & 11.16 & 6.09 \\
3 & 92.5 & 3 & 3.16 & 0.95 \\
6B, 7B & 400 & 56.2 & 11.16 & 5.04 \\
8B & 545 & 104.33 & 13.53 & 7.71 \\
9B, 10B & 480 & 80.93 & 14.32 & 5.65 \\
\hline
\end{tabular}

to the experimental values for series $2 \mathrm{~B} / 8 \mathrm{~B}, 6 \mathrm{~B} / 9 \mathrm{~B}$ and $7 \mathrm{~B} /$ $10 \mathrm{~B}$, respectively: the simulated deformation is in very good agreement with the experimental ones, thus further validating the model. Two different comparisons are evaluated in the following: nt-ufc/nc and coarse-grained steel at equal weight, and at equal ballistic limit.

\subsubsection{Equal weight}

Two hybrids (coarse-grained steel and nt-ufc/nc hybrid) of the same composite thickness (20 layers) are compared in Fig. 20. The nt-ufc/nc hybrid exhibits a lower energy absorption and ballistic limit. However, the deformation achieved by nc/nt-ufc hybrid just prior to failure and measured in the impact direction is lower than the deformation of the coarse-grained sample at identical projectile velocity by $\sim 35 \%$, see Table 6 .

\subsubsection{Equal ballistic limit}

Two hybrids with similar ballistic limits a coarsegrained 10-layer hybrid and a nt-ufc/nc 20-layer hybridare compared in Fig. 21. The nt-ufc/nc hybrid shows the same energy absorption as the coarse-grained hybrid, but with a deformation lower by $\sim 42 \%$ in the velocity range below the ballistic limit, see Table 5 . Note that this is achieved at the cost of an increase in weight of about 25 $30 \%$.

\subsubsection{Discussion}

In terms of energy absorption per unit weight, the ratio of a characteristic energy to the areal density provides a quantity to evaluate the performance of each material, see Table 7. In Table 7, the energy is the impact energy at the ballistic limit, i.e. the minimum energy necessary to perforate the plate.

The results in Table 7 are graphically shown in Fig. 22 in terms of absorbed energy and energy per areal density. From this figure, it appears that composite alone (series 3 ) has a relatively poor performance despite its low weight. The coarse-grained steel/composite hybrid has a worse performance than plain steel (series 1) when impacted on the steel side (series $2 \mathrm{~A}$ ), but when impacted on composite (series 2B), it exhibits a better performance. The results also show that an increase in composite weight/thickness improves the overall performance (series 2-8, 6-9 and 7-10).

Finally, comparing series 2 to series $6-7$ and series 8 to series 9-10, the obvious choice for ballistic protection seems to be the coarse-grained steel hybrid, as it exhibits the highest ballistic limit and energy absorption per unit weight. ${ }^{1}$ Additionally, its performance is not as good as the current state-of-the-art materials, such as Kevlar laminate present in PASTG helmets, with an energy absorption of 200 $230 \mathrm{~J}$ (roughly twice our best results, see Table 7) for $V_{50}=600-650 \mathrm{~m} \mathrm{~s}^{-1}$ with an areal density of $11.23 \mathrm{~kg} \mathrm{~m}^{-2}$ $[30,29]$. However, the lower deformation exhibited by nc and nt-ufc hybrids can potentially make them relevant choices for some specific applications, such as those related to blunt trauma injury prevention. In such cases, the armor

\footnotetext{
${ }^{1}$ Note, however, that, based on the discussion in Section 5.3, increasing the composite layer thickness is expected to eventually reverse this tendency at a given composite thickness threshold.
} 


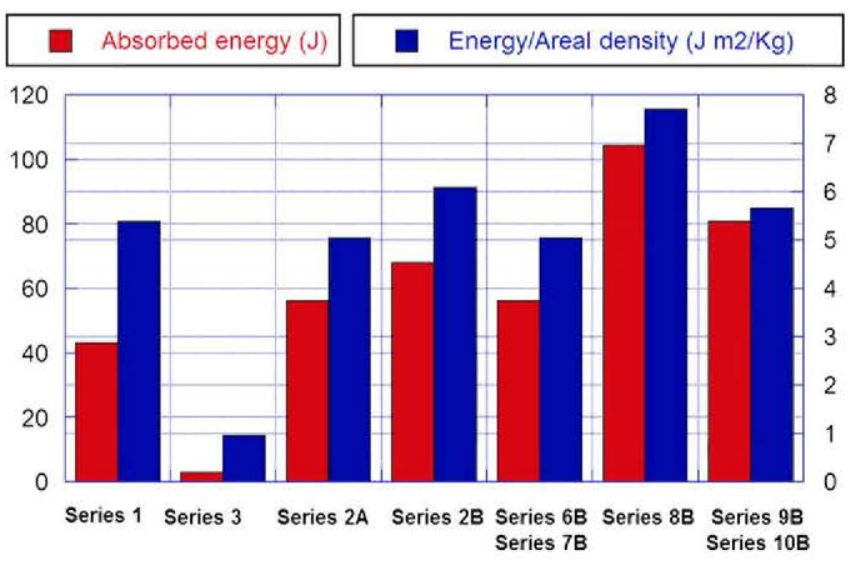

Fig. 22. Graph of the results shown in Table 7.

defeats the projectile but at the cost of a degree of elastic/ plastic deformation which can lead to serious injuries or even death. Some studies point out the importance of the clearance between helmet and skull [67], with distances greater than $11-12 \mathrm{~mm}$ needed to prevent skull fracture. A thin layer of nc or nt-ufc steel in the inner liner of a helmet made of a composite strong enough (or another material spreading the shock) may help to reduce the deformation. According to our results, the 20-layer nc/nt-ufc hybrid absorbs as much energy as a 10-layer coarse-grained steel hybrid, with $40 \%$ less deformation for a weight penalty of roughly $25-30 \%$.

\section{Conclusions}

In this paper, we presented an experimental campaign supported by numerical simulations aimed at investigating the behavior of nanocrystalline and nanotwinned ultrafine crystal thin plates under ballistic loading conditions. It was shown that these materials exhibit a lower energy absorption and ballistic limit than their coarse-grained counterparts. This decrease is directly related to the main failure mechanism taking place, shear plugging, and a change in the stress triaxiality evolution, drastically different from uniaxial deformation, where these metals were shown to exhibit higher strength and ductility for (nt-ufc), both at low and moderately high strain rates.

Placing a composite plate in front of the metal plate was shown to be an effective way to raise the relative energy absorption of the plate (overall and per unit weight). The composite, which absorbs a low amount of energy, helps to spread the shock over a wider surface, increasing the effective energy absorption area of the steel plate.

Finally, the deformation of the nanotwinned ultrafine crystals and nanocrystalline steels compared with their coarse-grained counterparts, when impacted at the same velocity just below ballistic limits, was shown to be roughly $40 \%$ lower, both at equal weight and equal ballistic limit. A nanocrystalline hybrid plate can thus offer the same level of protection as a coarse-grained hybrid, with $40 \%$ less deformation, at a cost of an increase in weight of $25-30 \%$. Such improvement could find a use in personal armor systems such as helmets, where clearance between the inner layer and the skull is vital to avoid injuries and where a thin sheet of nanocrystalline metals could thus participate in lowering the deformation. Additionally, it was emphasized that thicker composite plates or more efficient "spreading" front plates would lead eventually to better ballistic limits at equal weight. Future studies will tackle this proposition.

\section{Acknowledgements}

The authors thank Silvia Hernández and Vanesa Martínez for their help with the composites processing and Prof. Carlos González for many fruitful discussions on the matter. Y.Z. acknowledges China Scholarship Section for supporting the research in the Massachusetts Institute of Technology. M.D. would like to acknowledge the support by the ONR Grant N00014-08-1-0510 and the support from the Advanced Materials for Micro and Nano Systems Programme of the Singapore-MIT Alliance (SMA). J.L. is grateful for the support from the Research Grants Council for the Hong Kong Special Administrative Region of China under grants CityU8/CRF/08 and GRF/CityU519110, the Croucher Foundation CityU9500006. A.J. acknowledges support from the Juan de la Cierva grant from the Spanish Ministry of Science and Innovation, from the Amarout grant from the European Union and from the ESTRUMAT-S2009/MAT-1585 grant (Madrid Regional Government).

\section{Appendix A. Supplementary data}

Supplementary data associated with this article can be found, in the online version, at doi: $10.1016 / \mathrm{j}$.actamat. 2011.11.029.

\section{References}

[1] Rack H, Cohen M. Mater Sci Eng 1970;6:320-6.

[2] Morris Jr J. In: Takaki S, Maki T, editors. International symposium on ultrafine grained steels. Tokyo (Japan): Iron and Steel Inst.; 2001. p. 3441 .

[3] Arifvianto B, Suyitno, Mahardika M, Dewo P, Iswanto P, Salim U. Mater Chem Phys 2011;125:418-26.

[4] Hall E. J Mech Phys Solids 1953;1:227-33.

[5] Petch N. Prog Met Phys 1954;5:1-52.

[6] Gleiter H. Prog Mater Sci 1989;33:223-315.

[7] Jérusalem A, Radovitzky R. Modell Simul Mater Sci Eng 2009;17:025001.

[8] Schiøtz J, Jacobsen K. Science 2003;301:1357-9.

[9] Lu L, Chen X, Huang X, Lu K. Science 2003;323:607-10.

[10] Zhang H, Hei Z, Liu G, Lu J, Lu K. Acta Mater 2003;51:1871-81.

[11] Chen X, Lu J, Lu L, Lu K. Scr Mater 2005;52:1039-44.

[12] Lin Y, Lu J, Wang L, Xu T, Xue Q. Acta Mater 2006;54:5599-605.

[13] Dao M, Lu L, Asaro R, Hosson JD, Ma E. Acta Mater 2007;55:4041-65.

[14] Schiøtz J, Tolla FD, Jacobsen K. Nature 1998;391:561-3.

[15] Yip S. Nature 1998;391:532-3. 
[16] Swygenhoven HV, Spaczer M, Caro A, Farcas D. Phys Rev B 1999;60:22-5.

[17] Schiøtz J, Vegge T, Tolla FD, Jacobsen K. Phys Rev B 1999;60:11971-83

[18] Yamakov V, Wolf D, Phillpot S. Nat Mater 2002;1:1-4.

[19] Lund A, Nieh T, Schuh C. Phys Rev B 2004;69:012101.

[20] Lund A, Schuh C. Acta Mater 2005;53:3193-205.

[21] Bringa E, Caro A, Wang Y, Victoria M, McNaney J, Remington B, et al. Science 2005;309:1838-41.

[22] Lu K, Lu L, Suresh S. Science 2009;324:349-52.

[23] Lu L, Shen Y, Chen X, Qian L, Lu K. Science 2004;304:422-6.

[24] Lu L, Schwaiger R, Shan Z, Dao M, Lu K, Suresh S. Acta Mater 2005;53:2169-79.

[25] Shen Y, Lu L, Lu Q, Jin Z, Lu K. Scr Mater 2005;52:989-94.

[26] Dao M, Lu L, Shen Y, Suresh S. Acta Mater 2006;54:5421-32.

[27] Shen Y, Lu L, Dao M, Suresh S. Scr Mater 2006;55:319-22.

[28] Jérusalem A, Dao M, Suresh S, Radovitzky R. Acta Mater 2008; $56: 4647-57$.

[29] Thama C, Tan V, Lee H. Int J Impact Eng 2008;35:304-18.

[30] Folgar F, Scott B, Walsh S, Wolbert J. 23rd International symposium on ballistics, Tarragona; 2007.

[31] Armellino RA. US Patent 3971072 - lightweight armor and method of fabrication; 1976.

[32] Pinnacle Armor, Dragon Skin; 2010. <http://www.pinnaclearmor.com/body-armor/dragon-skin/ $>$.

[33] C Andersen Jr, J Wilbeck, S Bodner, J Lankford, SA Mullin, J Walker. Short course on penetration mechanics. San AntonioHouston: Southwest Research Institute; 2010. p.33.

[34] Report T. Mater Des 1993;14:133-5.

[35] Ipson T, Recht R. J Appl Mech 1963;30:385-91.

[36] Ipson T, Recht R. Exp Mech 1975;15:249-57.

[37] Corran R, Shadbolt P, Ruiz C. Int J Impact Eng 1983;1:3-22.

[38] Awerbuch J, Bodner S. Int J Solids Struct 1974;10:671-84.

[39] Awerbuch J, Bodner S. Int J Solids Struct 1974;10:685-99.

[40] Ben-Dor G, Dubinsky A, Elperin T. Appl Mech Rev 2005;58:355-71.

[41] Sierakowski R, Nevill Jr G, Ross C, Jones E. Follow-on studies on the ballistic impact of composite materials. AFATL-TR-70-87. Air Force Armament Laboratory, Eglin Air Force Base; 1970.

[42] López-Puente J, Zaera $R$, Navarro C. Int J Solids Struct 2006:44:2837-51.

[43] López-Puente J, Varas D, Loya J, Zaera R. Composites Part A $2009: 40: 1223-30$.
[44] López-Puente J, Zaera R, Navarro C. Composites Part A 2008:39:374-87.

[45] Abrate S. Appl Mech Rev 1991;44:155-90.

[46] Abrate S. Appl Mech Rev 1994;47:517-44.

[47] Dean J, Dunleavy C, Brown P, Clyne T. Int J Impact Eng 2009;36:1250-8.

[48] Arias A, Zaera R, López-Puente J, Navarro C. Compos Struct 2003;61:151-9.

[49] Lopes C, Seresta O, Coquet Y, Gürdal Z, Camanho P, Thuis B. Compos Sci Technol 2009;69:926-36.

[50] Lopes C, Camanho P, Gürdal Z, Maimí P, González E. Compos Sci Technol 2009;69:937-47.

[51] Vicente JF, Jérusalem A, Zhang Y, Dao M, Lu J, Gálvez F. Ballistic testing of nanocrystalline hybrid plates. In: 26th International symposium on ballistics event; 2011.

[52] Tao N, Wang Z, Tong W, Sui M, Lu J, Lu K. Acta Mater 2002;50:4603-16.

[53] Lu J, Lu K. US Patent 7,147,726 - mechanical method for generating nanostructures and mechanical device for generating nanostructures; 2006.

[54] Wang Y, Wang K, Pan D, Lu K, Hemkera K, Ma E. Scr Mater $2003 ; 48: 1581-6$.

[55] Zhu K, Vassel A, Brisset F, Lu K, Lu J. Acta Mater 2004;52:4101-10.

[56] Chen A, Ruan H, Wang J, Chan H, Wang Q, Li Q, et al. Acta Mater 2011;59:3697-709.

[57] Wua X, Tao N, Hong Y, Liu G, Xu B, Lu J, et al. Acta Mater 2005;53:681-91.

[58] Zhang H, Wang L, Hei Z, Liu G, Lu J, Lu K. Z Metallkd 2003;94:1143-7.

[59] Johnson G, Cook W. Eng Fract Mech 1985;21:31-48.

[60] Zerilli F, Armstrong R. J Appl Phys 1987;61:1816-25.

[61] Johnson G, Cook W. In: Proceeding of the seventh international symposium on ballistics, vol. 541; 1983.

[62] Borvik T, Langseth M, Hopperstad O, Malo A. Int J Impact Eng 1999:22:855-86.

[63] Gupta N, Iqbal M, Sekhon G. Int J Impact Eng 2006;32:192-1944.

[64] Hancock J, Mackenzie A. J Mech Phys Solids 1976;24:147-60.

[65] Dabboussi W, Nemes J. Int J Mech Sci 2005;47:1282-99.

[66] SIMULIA. Abaqus explicit; 2010.

[67] Sarron J-C, Dannawi M, Faure A, Calliou J, Cunha JD, Robert R. J Trauma 2004;57:236-42. 